Review Article

\title{
COVID-19 Vaccination during Pregnancy in Southeast Asia
}

\author{
Jia Ni Kwan', Hong Chuan Loh ${ }^{1}$, Irene Looi ${ }^{1,2}$ \\ Article History \\ ${ }^{1}$ Clinical Research Centre, Hospital Seberang Jaya, Ministry of Health \\ Malaysia, 13700 Seberang Jaya, Penang, Malaysia; kwan.jia.ni@gmail.com \\ Received: 5 July 2021; \\ (JNK) \\ Received in Revised Form: \\ ${ }^{2}$ Medical Department, Hospital Seberang Jaya, Ministry of Health Malaysia, \\ 13700 Seberang Jaya, Penang, Malaysia; irenelooi@yahoo.com (IL) \\ 6 August 2021; \\ Accepted: 9 August 2021; \\ *Corresponding author: Hong Chuan Loh, lohhongchuan@gmail.com (HCL)
}

Available Online: 19

August 2021

\begin{abstract}
Southeast Asia is rapidly becoming the region hit hardest by coronavirus disease (COVID-19), as evidenced by the surging daily number of new confirmed cases and deaths. The COVID-19 crisis continues to worsen with the entry of the more transmissible variants of concern, primarily the Delta variant of severe acute respiratory syndrome coronavirus 2 (SARS-CoV-2) which was first identified in India. Pregnant women are among the vulnerable population groups at risk of suffering from severe COVID-19 and may experience poor pregnancy and neonatal outcomes due to the infection. Vaccination seems to be the most effective strategy to curb the pandemic and secondarily by social distancing, wearing face masks and practising hand hygiene. There has been limited yet reassuring evidence in support of vaccinating pregnant women against COVID-19. We sought to review the latest evidence regarding the safety, immunogenicity and reactogenicity of COVID-19 vaccines in pregnant women as well as the recommendations and guidance provided by the public health authorities in the countries in Southeast Asia.
\end{abstract}

Keywords: COVID-19; vaccination; pregnancy; Southeast Asia; pandemic

\section{Introduction}

The coronavirus disease (COVID-19) caused by severe acute respiratory syndrome coronavirus 2 (SARS-CoV-2) has caused a pandemic worldwide. Globally, as of the $24^{\text {th }}$ of July 2021, there have been more than 190 million cases and greater than four million deaths as reported by the World Health Organization (WHO). Southeast Asia ranked third in the total number of confirmed cases and deaths after America and Europe, having over 37 million cases and more than 500,000 deaths attributable to COVID-19 ${ }^{[1]}$. The virus was first spread from Wuhan, China to Southeast Asia on the $13^{\text {th }}$ of January 2020 when the first COVID-19 case outside China was detected in Thailand ${ }^{[2-4]}$. Entry of the more virulent and highly transmissible Delta variant of SARS-CoV-2 which was first detected in India in the late 2020 
has worsened the COVID-19 crisis across most of Southeast Asia ${ }^{[5]}$, leading to new record highs for COVID-19 cases and deaths in many countries in Southeast Asia such as Indonesia, Myanmar and Malaysia.

Indonesia has become the new epicenter of the COVID-19 pandemic in Asia. Being the largest country in Southeast Asia, it was hit worst by the pandemic, having the highest number of cases and deaths as compared to other countries in the region. From the beginning of the pandemic until July 2021, Indonesia recorded more than three million confirmed cases of COVID-19 and 84,766 deaths ${ }^{[6]}$. According to data from the Indonesian Obstetrics and Gynaecology Association (POGI) Reproductive Tract Infection Working Group, there were 536 cases of COVID-19 in pregnant women from April 2020 to April 2021. Up to $72 \%$ of them were at above 37 weeks of gestation, $4.5 \%$ needed treatment in the intensive care unit (ICU) and approximately $3 \%$ succumbed to COVID-19 ${ }^{[7]}$.

Evidence has shown that pregnant women infected with COVID-19, especially in the late second or third trimester have a higher likelihood of getting admitted to the ICU and require invasive ventilation ${ }^{[8]}$. They are especially more vulnerable to severe COVID-19 which may lead to maternal death if they have pre-existing comorbidities such as hypertension, diabetes and obesity ${ }^{[9,10]}$. In addition, complications like pre-eclampsia, emergency Caesarean section and preterm delivery are more likely to occur in pregnancy with COVID-19 ${ }^{[11]}$. Besides the association of COVID-19 in pregnancy with adverse maternal outcomes, it is also reported to impact negatively on the foetus. Increased incidences of stillbirth, neonatal deaths, admission to the neonatal ICU, foetal distress and poor APGAR score were reported in babies born to mothers with COVID-19 ${ }^{[9]}$.

Given the emerging evidence of the association between COVID-19 and negative maternal-foetal outcomes, it is reasonable and justifiable to vaccinate pregnant women against an infection that could potentially harm the mother and foetus. A variety of vaccine candidates have been developed and authorised for emergency use by the WHO, comprising inactivated virus vaccines, protein subunit vaccines, mRNA vaccines and recombinant viral vector vaccines ${ }^{[12]}$. Many guidelines and recommendations were published by governmental public health agencies as well as healthcare organisations such as the WHO and the Centers for Disease Control and Prevention (CDC) regarding the administration of COVID-19 vaccines in pregnant women ${ }^{[13]}$. The CDC and the Advisory Committee on Immunization Practices have released clinical guidance stating that pregnant women are eligible for and can receive COVID-19 vaccination ${ }^{[14]}$.

In this study, we aim to review the evidence regarding COVID-19 vaccination in pregnant women as well as current COVID-19 vaccination guidance for pregnant women in Southeast Asia. 


\section{COVID-19 Vaccination in Pregnant Women}

\subsection{Immunogenicity}

There have been studies looking into the immunogenicity of COVID-19 vaccination in pregnant women. Results showed that the vaccine-induced antibody titres in pregnant women who had received COVID-19 mRNA vaccines were equivalent to non-pregnant women. COVID-19 mRNA vaccines were shown to be able to produce robust humoral immunity in pregnant women. The immunogenicity and reactogenicity of the vaccines were comparable to non-pregnant populations as evidenced by the CD4 and CD8 T-cell responses as well as the presence of binding, neutralising and functional non-neutralising antibodies seen in vaccinated pregnant women ${ }^{[15,16]}$. Maternal antibodies were detected as early as five days after receiving the first dose of vaccine, with the IgG levels increasing significantly over time $^{[17]}$. Vaccination against COVID-19 was also shown to elicit a greater antibody response than natural SARS-CoV-2 infection ${ }^{[15]}$.

\subsection{Safety}

A recent study reported on the safety of mRNA COVID-19 vaccines, BNT162b2 (Pfizer-BioNTech) and mRNA-1273 (Moderna) in pregnant women using the data obtained from the v-safe surveillance system and pregnancy registry in the United States (US). This study involved 35,691 pregnant women; 54\% of them received the Pfizer-BioNTech vaccine while $46 \%$ received the Moderna vaccine. It was found that the mRNA vaccines did not cause an increase in the incidence of adverse pregnancy and neonatal outcomes such as spontaneous abortion, preterm birth, congenital anomalies and neonatal death ${ }^{[18]}$. Another observational case-control study conducted in Israel also reported similar results in terms of obstetric and neonatal outcomes in pregnant women who had received Pfizer's BNT162b2 COVID-19 vaccine $^{[19]}$. Besides, there was no reported increase in the incidence of abnormal placental findings such as decidual arteriopathy, chronic villitis, foetal vascular malperfusion and chronic histiocytic intervillositis in vaccinated pregnant women ${ }^{[20]}$. Overall, no obvious safety concerns with regard to pregnancy or neonatal outcomes were found to be associated with COVID-19 vaccination in pregnant women.

\subsection{Reactogenicity}

V-safe survey data reported that the overall reactogenicity profile was similar between the pregnant and non-pregnant groups. Pain at the injection site, headache, fatigue and myalgia were the most commonly reported local and systemic reactions for both the Pfizer-BioNTech vaccine and the Moderna vaccine ${ }^{[18]}$. Another cross-sectional study also compared the side effect profile of mRNA COVID-19 vaccines reported by pregnant and 
non-pregnant healthcare workers. Among 1,029 healthcare workers enrolled in the study, 38 were pregnant, 20 of them received the Pfizer-BioNTech vaccine while 18 received the Moderna vaccine. The side effects profile seemed to be similar in both groups immediately after and in the early post-vaccination period as there was no statistically significant difference observed ${ }^{[21]}$. A similar result was seen in another study, with myalgia, arthralgia and headache significantly less commonly reported by the pregnant women receiving Pfizer's BNT162b2 COVID-19 vaccine ${ }^{[19]}$.

\section{COVID-19 Vaccine Recommendations for Pregnant Women in Southeast Asia}

The latest guidelines and COVID-19 vaccination practices adopted by each country in Southeast Asia for pregnant women are shown in Table 1. Our search regarding the most updated recommendations was up to the $24^{\text {th }}$ of July 2021.

\subsection{Malaysia}

On the $24^{\text {th }}$ of May 2021, the Special Committee on Ensuring Access to COVID-19 Vaccine Supply (JKJAV) released an advisory on vaccination for pregnant and lactating women. Among the three vaccines available in Malaysia at that point in time, PfizerBioNTech vaccine was the only vaccine deemed to be suitable for pregnant women if administered between 14 to 33 weeks of pregnancy or post-delivery ${ }^{[22]}$. AZD1222 (OxfordAstraZeneca) and CoronaVac (Sinovac), the other two vaccines available in Malaysia at the time, were not recommended for pregnant women. Nonetheless, a month later on $25^{\text {th }}$ June 2021, the advisory was updated to include the Pfizer-BioNTech, Oxford-AstraZeneca and Sinovac vaccines as suitable for pregnant women between 14 to 33 weeks of pregnancy ${ }^{[23]}$. According to the COVID-19 vaccination guideline regarding pregnancy published by the Ministry of Health $(\mathrm{MOH})$, since the Oxford-AstraZeneca vaccine is not a live vaccine, it is not contraindicated in pregnancy. However, there is a rare but potential risk of vaccineinduced immune thrombotic thrombocytopaenia (VIIT) which the pregnant women would want to discuss with their obstetricians. Meanwhile, Sinovac vaccine was recommended based on WHO's interim guidelines since the benefits outweighed the risks. Both OxfordAstraZeneca and Sinovac vaccines can be administered if the woman conceives after getting first dose of the respective vaccine. The guideline also mentioned that there was no contraindication for the use of Ad5-nCoV (CanSinoBio) and Ad26.CoV2.S (Janssen) vaccines which were granted conditional approval for emergency use on $15^{\text {th }}$ June 2021 . However, the availability of safety data for these two vector-based vaccines was limited, hence Pfizer-BioNTech vaccine remained the preferred option for pregnant women ${ }^{[24]}$.

The recommended window for vaccination of pregnant women was between 14 and 33 weeks as the period before 14 weeks is the period of organogenesis. Given the unknowns, 
healthcare professionals would like to minimise exposure to vaccines during organogenesis since it is possible that vaccination might affect organ formation during embryonic development. Meanwhile, the upper limit was set at 33 weeks to ensure that pregnant women gained sufficient immunity and protection before the late second trimester to prevent significant implications if they contract COVID-19 during the vulnerable late second and third trimester. However, pregnant women can still get the vaccine after 33 weeks of gestation upon consultation with their doctor ${ }^{[25]}$.

Up to $25^{\text {th }}$ June 2021 , a total of 109,607 pregnant women had voluntarily registered for the COVID-19 vaccination via MySejahtera, a mobile application that allows the citizens to register for vaccination ${ }^{[26]}$.

\subsection{Singapore}

The Expert Committee on COVID-19 Vaccination (EC19V) published vaccination guidelines for subgroups of individuals, including pregnant women on the $31^{\text {st }}$ of May 2021. It reported that there was no evidence to suggest Pfizer-BioNTech vaccine or Moderna vaccine may bring negative consequences to the health of the mother or child. However, pregnant women were advised to discuss and receive endorsement from their obstetrician before getting vaccinated. Following updates on the vaccination programme, the registration for pregnant women commenced on $4^{\text {th }}$ June $2021^{[27]}$. In June 2021, the College of Obstetricians and Gynaecologists Singapore (COGS) and Obstetrical \& Gynaecological Society of Singapore (OGSS) published a joint guideline on COVID-19 vaccination for pregnant women. It was recommended that pregnant women might get their vaccination after 12 weeks of pregnancy ${ }^{[28]}$.

The local availability of vaccines will determine the choice of vaccine for pregnant women. At the time of this writing, vaccines available in Singapore are Pfizer-BioNTech vaccine, Moderna vaccine and Sinovac vaccine. However, Sinovac vaccine was only started being administered on $15^{\text {th }}$ June 2021 under the Special Access Route in private clinics. It was not being included in Singapore's national vaccination programme as the MOH claimed that the evaluation of Sinovac vaccine's safety and efficacy had yet to be completed ${ }^{[29]}$. Hence, only the mRNA vaccines, Pfizer-BioNTech vaccine and Moderna vaccine were administered to pregnant women ${ }^{[28]}$.

\subsection{Thailand}

The Royal Thai College of Obstetricians and Gynaecologists and the Perinatal Society of Thailand recommended that every pregnant mother should be vaccinated against COVID-19 after the $12^{\text {th }}$ week of pregnancy ${ }^{[30]}$. Thailand's Food and Drug Administration 
(FDA) had approved six COVID-19 vaccines for emergency use which were OxfordAstraZeneca vaccine, Sinovac vaccine, Janssen vaccine, Moderna vaccine, Pfizer-BioNTech vaccine and BBIBP-CorV (Sinopharm) ${ }^{[31]}$. The Ministry of Public Health recommended Sinovac vaccine as the choice of vaccine for pregnant women since it is an inactivated vaccine. Meanwhile, Oxford-AstraZeneca vaccine, being a viral vector vaccine raised concern since there is a high likelihood of developing maternal pyrexia post vaccination ${ }^{[32]}$.

\subsection{Philippines}

The Department of Health reported that pregnant women are not contraindicated to get their COVID-19 vaccine. They were advised to get vaccinated only after the first trimester of pregnancy ${ }^{[33]}$. Regarding the choice of COVID-19 vaccines, among the eight vaccines, namely Sinopharm vaccine, Pfizer-BioNTech vaccine, Sinovac vaccine, Janssen vaccine, Moderna vaccine, AstraZeneca vaccine, Covaxin (Bharat Biotech) and Sputnik V (Gamaleya) that had been authorised by the Philippines FDA for an emergency use authorisation, Gamaleya vaccine was the only vaccine not recommended for pregnant women $^{[34,35]}$.

\subsection{Indonesia}

On the $22^{\text {nd }}$ of June 2021, POGI urged vulnerable pregnant women to get their COVID-19 vaccination following spikes in severe COVID-19 cases in pregnant women and the entry of the more contagious Delta variant of SARS-CoV-2 into Indonesia. Pregnant women, especially those with high-risk conditions such as advanced maternal age (more than 35 years), body mass index (BMI) above $40 \mathrm{~kg} / \mathrm{m}^{2}$, comorbidities of diabetes and hypertension as well as those working in healthcare settings, were strongly recommended for vaccination. POGI also recommended that pregnant women should get their vaccines between 12 to 33 weeks of pregnancy ${ }^{[7]}$. However, the type of vaccines to be administered to pregnant women was not specified.

\subsection{Brunei}

There was no specific guideline for COVID-19 vaccination in pregnant women in Brunei. However, in a document titled "Frequently Asked Questions on COVID-19 Vaccines" published by the MOH, pregnant women were advised to discuss vaccination with their doctors before getting vaccinated ${ }^{[36]}$. There were five COVID-19 vaccine candidates for Brunei citizens, namely Pfizer-BioNTech vaccine, Moderna vaccine, Oxford-AstraZeneca vaccine, Sinopharm vaccine and Janssen vaccine ${ }^{[37]}$. The MOH had published health advisories for two of the COVID-19 vaccines, Sinopharm vaccine and Oxford-AstraZeneca vaccine. Neither Sinopharm vaccine nor Oxford-AstraZeneca vaccine was recommended for 
pregnant women due to a lack of clinical trial data at the time of publication of the $\operatorname{advisories}^{[38,39]}$.

\subsection{Vietnam, Laos, Cambodia}

The WHO's Representative Office for Vietnam, Laos and Cambodia did not recommend the administration of COVID-19 vaccines to pregnant women unless the benefits outweighed the risks. It was recommended that pregnant healthcare workers who have a high risk of exposure and pregnant women with comorbidities who have a higher risk of getting severe COVID-19 should be vaccinated after discussing with their doctors. Further information about vaccine choices and the appropriate time for vaccination was not provided $^{[40-42]}$.

\subsection{Myanmar, Timor-Leste}

Data regarding COVID-19 vaccination for pregnant women in Myanmar and TimorLeste are unavailable, hence they are not included in our review. 
Table 1. COVID-19 vaccine recommendations for pregnant women in Southeast Asia.

\begin{tabular}{|c|c|c|c|c|c|}
\hline Country & Vaccines available & $\begin{array}{c}\text { Time of } \\
\text { vaccination }\end{array}$ & Guidelines & Last updated & Recommendations \\
\hline \multirow[t]{4}{*}{ Malaysia $^{[43]}$} & $\begin{array}{l}\text { Pfizer-BioNTech* } \\
\text { Oxford- } \\
\text { AstraZeneca* }\end{array}$ & \multirow[t]{4}{*}{$\begin{array}{l}\text { 14-33 weeks of } \\
\text { pregnancy }\end{array}$} & \multirow[t]{4}{*}{$\begin{array}{l}\text { Guidelines on COVID-19 } \\
\text { Vaccination in Pregnancy and } \\
\text { Breastfeeding }\end{array}$} & \multirow[t]{4}{*}{23 June 2021} & $\begin{array}{l}\text { "COVID-19 vaccination should be advocated in } \\
\text { pre-pregnancy care, especially for front liners } \\
\text { and mothers with identifiable risk factors and } \\
\text { those seeking infertility treatment." }\end{array}$ \\
\hline & & & & & - $\quad$ "Based on virology principles, mRNA, vector- \\
\hline & CanSinoBio & & & & \\
\hline & Janssen & & & & $\begin{array}{l}\text { mothers. Although evidence continues to emerge } \\
\text { as more pregnant mothers are included in the } \\
\text { study cohort, current data suggest that mRNA } \\
\text { vaccines are the preferred option. Live vaccines } \\
\text { are contraindicated in pregnancy." }\end{array}$ \\
\hline \multirow[t]{3}{*}{ Singapore ${ }^{[29]}$} & \multirow{3}{*}{$\begin{array}{l}\text { Pfizer-BioNTech* } \\
\text { Moderna* } \\
\text { Sinovac }\end{array}$} & \multirow[t]{3}{*}{$\begin{array}{l}\text { After } 12 \text { weeks of } \\
\text { pregnancy }\end{array}$} & \multirow{2}{*}{$\begin{array}{l}\text { Expanding Singapore's } \\
\text { vaccination programme: } \\
\text { Updated vaccination guidelines } \\
\text { for sub-groups of individuals } \\
\text { and enhancing access for } \\
\text { seniors }\end{array}$} & \multirow[t]{2}{*}{31 May 2021} & $\begin{array}{l}\text { - "There is currently no evidence to suggest that } \\
\text { the Pfizer-BioNTech or Moderna vaccines may } \\
\text { cause harm to the mother or child." }\end{array}$ \\
\hline & & & & & $\begin{array}{l}\text { - "As there is less data available for pregnant } \\
\text { women, pregnant women should discuss with } \\
\text { their doctors to make an informed decision." }\end{array}$ \\
\hline & & & $\begin{array}{l}\text { COVID-19 Vaccination for } \\
\text { Pregnant Women, Breastfeeding } \\
\text { Women and Women Planning } \\
\text { to Conceive }{ }^{[28]}\end{array}$ & June 2021 & $\begin{array}{l}\text { "All pregnant and lactating women should be } \\
\text { provided information and offered COVID-19 } \\
\text { vaccination." } \\
\text { "Pregnant women should be offered vaccination } \\
\text { at the same time as the rest of the population, } \\
\text { based on their age and clinical risk group, if no } \\
\text { contraindications exist. As COVID-19 is } \\
\text { associated with more severe complications in the } \\
\text { later part of pregnancy, some women may } \\
\text { choose to delay their vaccine until after the first }\end{array}$ \\
\hline
\end{tabular}


- "The choice of vaccine administered is largely based on local availability. Currently, mRNA Vaccines (Pfizer-BioNTech's BNT162b2 and Moderna's mRNA-1273) are preferable to adenovirus vector vaccines for pregnant women and women younger than 50 years of age."

\begin{tabular}{|c|c|c|c|c|c|}
\hline Thailand $^{[31]}$ & $\begin{array}{l}\text { Oxford-AstraZeneca } \\
\text { Sinovac* } \\
\text { Janssen } \\
\text { Moderna } \\
\text { Sinopharm } \\
\text { Pfizer-BioNTech }\end{array}$ & $\begin{array}{l}\text { After } 12 \text { weeks of } \\
\text { pregnancy }\end{array}$ & $\begin{array}{l}\text { The Coronavirus Disease } 2019 \\
\text { Situation }^{[32]}\end{array}$ & 1 May 2021 & $\begin{array}{l}\text { - "The Department of Health, Ministry of Public } \\
\text { Health suggested that pregnant women should } \\
\text { receive COVID-19 vaccines." } \\
\text { - "The appropriate time for pregnant women } \\
\text { should be vaccinated after 12-week pregnancy." } \\
\text { - "Sinovac vaccine is recommended for pregnant } \\
\text { women because it is an inactivated vaccine." } \\
\text { "While AstraZeneca vaccine is a viral vector } \\
\text { vaccine, it has a high probability of developing a } \\
\text { fever after vaccination." } \\
\text { "Women who plan to become pregnant and } \\
\text { lactating mothers can be vaccinated like general } \\
\text { persons." }\end{array}$ \\
\hline Philippines ${ }^{[34]}$ & $\begin{array}{l}\text { Sinopharm } \\
\text { Pfizer-BioNTech } \\
\text { Sinovac } \\
\text { Bharat Biotech } \\
\text { Janssen } \\
\text { Moderna } \\
\text { Oxford-AstraZeneca }\end{array}$ & $\begin{array}{l}\text { After first } \\
\text { trimester of } \\
\text { pregnancy }\end{array}$ & $\begin{array}{l}\text { Can Pregnant Women Get the } \\
\text { Covid-19 Vaccine? }\end{array}$ & 30 March 2021 & $\begin{array}{l}\text { - "Pregnancy is not a contraindication to getting } \\
\text { the COVID-19 vaccine (except for the Gamaleya } \\
\text { vaccine, which shall not be administered to the } \\
\text { pregnant and breastfeeding populations)." } \\
\text { "Pregnant women can get the vaccine with } \\
\text { precaution, given that there is limited data on } \\
\text { pregnant women from clinical studies." }\end{array}$ \\
\hline
\end{tabular}


Gamaleya

\begin{tabular}{|c|c|c|c|c|c|}
\hline Indonesia & $\begin{array}{l}\text { Sinopharm } \\
\text { Sinovac } \\
\text { Moderna } \\
\text { Oxford-AstraZeneca } \\
\text { Pfizer-BioNTech }\end{array}$ & $\begin{array}{l}12 \text { to } 33 \text { weeks of } \\
\text { pregnancy }\end{array}$ & $\begin{array}{l}\text { POGI's Recommendation } \\
\text { Regarding the Spike in Cases of } \\
\text { Pregnant Women with COVID- } \\
19^{[7]}\end{array}$ & 22 June 2021 & $\begin{array}{l}\text { - "The POGI has recommended vaccination for } \\
\text { pregnant women, especially high-risk pregnant } \\
\text { women, namely those aged over } 35 \text { years, } \\
\text { pregnant women with a BMI } 1 \text { above } 40 \text { and } \\
\text { comorbidities of diabetes and hypertension, as } \\
\text { well as for pregnant health workers." } \\
\text { - "Injecting COVID-19 vaccine to women with } \\
\text { pregnancy ages of over } 12 \text { weeks to avoid risks." } \\
\text { "POGI recommended pregnant women be } \\
\text { vaccinated } 33 \text { weeks into their pregnancy, which } \\
\text { was meant to create protection for their } \\
\text { foetuses." }\end{array}$ \\
\hline Brunei $^{[37]}$ & $\begin{array}{l}\text { Moderna } \\
\text { Oxford-AstraZeneca } \\
\text { Sinopharm }\end{array}$ & - & $\begin{array}{l}\text { Information on the Sinopharm } \\
\text { COVID-19 Vaccine }{ }^{[38]}\end{array}$ & - & $\begin{array}{l}\text {-MOH does not recommend pregnant group to } \\
\text { receive the Sinopharm vaccine due to lack of } \\
\text { clinical trial data at present. This may be revised } \\
\text { as more evidence becomes available." }\end{array}$ \\
\hline & $\begin{array}{l}\text { Pfizer-BioNTech } \\
\text { Janssen }\end{array}$ & & $\begin{array}{l}\text { Information on the Oxford- } \\
\text { AstraZeneca COVID-19 } \\
\text { Vaccine }^{[39]}\end{array}$ & - & $\begin{array}{l}\text { - "The AstraZeneca vaccine is not currently } \\
\text { recommended for pregnant women." }\end{array}$ \\
\hline Vietnam & $\begin{array}{l}\text { Oxford-AstraZeneca } \\
\text { Gamaleya } \\
\text { Sinopharm } \\
\text { Pfizer-BioNTech } \\
\text { Moderna }\end{array}$ & - & $\begin{array}{l}\text { Viet Nam COVID-19 Situation } \\
\text { Report } 50^{[40]}\end{array}$ & 11 July 2021 & $\begin{array}{l}\text { - "While pregnancy puts women at higher risk of } \\
\text { severe COVID-19, very little data are available } \\
\text { to assess vaccine safety in pregnancy." } \\
\text { - } \quad \text { Pregnant women may receive the vaccine if the } \\
\text { benefit of vaccinating a pregnant woman } \\
\text { outweighs the potential vaccine risks." } \\
\text { "For this reason, pregnant women at high risk of } \\
\text { exposure to SARS-CoV-2 (eg. health workers) or } \\
\text { who have comorbidities which add to their risk }\end{array}$ \\
\hline
\end{tabular}

- "If a pregnant woman is part of a group recommended for vaccination, vaccination can
be offered."

"The POGI has recommended vaccination for comorbidities of diabetes and hypertension, as "Injecting COVID-19 vaccine to women with ency ages of over 12 weeks to avoid risks." was meant to create protection for their

"MOH does not recommend pregnant group to (hinopharm vaccine due to lack of clinical trial data at present. This may be revised

"The AstraZeneca vaccine is not currently (1) who have comorbidities which add to their risk 
of severe disease, may be vaccinated in

consultation with their health care provider."

\begin{tabular}{|c|c|c|c|c|c|}
\hline Laos & $\begin{array}{l}\text { Pfizer-BioNTech } \\
\text { Oxford-AstraZeneca } \\
\text { Gamaleya } \\
\text { Sinopharm } \\
\text { Sinovac }\end{array}$ & - & $\begin{array}{l}\text { COVID-19 Vaccines Frequently } \\
\text { asked questions (FAQs) }\end{array}$ & 7 April 2021 & $\begin{array}{l}\text { - "The available data on COVID-19 vaccines are } \\
\text { insufficient to assess vaccine efficacy or vaccine- } \\
\text { associated risks in pregnancy. As data from } \\
\text { studies become available, recommendations on } \\
\text { vaccination will be updated accordingly." } \\
\text { "In the interim, WHO recommends not to use } \\
\text { COVID-19 vaccines in pregnant women unless } \\
\text { the benefit of vaccinating a pregnant woman } \\
\text { outweighs the potential vaccine risks, such as in } \\
\text { health workers at high risk of exposure and } \\
\text { pregnant women with comorbidities placing } \\
\text { them in a high-risk group for severe COVID-19." }\end{array}$ \\
\hline Cambodia & $\begin{array}{l}\text { Oxford-AstraZeneca } \\
\text { Sinopharm } \\
\text { Sinovac }\end{array}$ & - & $\begin{array}{l}\text { Frequently asked questions: } \\
\text { Safety of Covid-19 Vaccines }\end{array}$ & 25 March 2021 & $\begin{array}{l}\text { - "Given the current lack of data on safety and } \\
\text { efficacy regarding COVID-19 vaccines for } \\
\text { pregnant women, they are not prioritised or } \\
\text { recommended for COVID-19 vaccination at this } \\
\text { point in time. Studies are ongoing." }\end{array}$ \\
\hline
\end{tabular}

* Vaccines recommended for pregnant women 


\section{Ongoing Vaccine Trials and Observational Studies on Pregnant Women}

Since pregnant women are at high risk of getting severe COVID-19, vaccination is undoubtedly a crucial prevention strategy. Nevertheless, there are limited data regarding the efficacy and safety of COVID-19 vaccines in pregnancy as pregnant women were being excluded from the first wave of vaccine trials due to safety concerns. This caused pregnant women to be denied vaccines that would have offered protection for themselves and their babies. Initially, there were inconsistent advice and recommendations from the public health, governmental and professional authorities globally regarding COVID-19 vaccination during pregnancy, leading to confusion and hesitancy among pregnant women and healthcare providers $^{[44]}$.

Pregnant women should be considered candidates to receive COVID-19 vaccination and the safety of vaccine products to be administered during pregnancy is of utmost importance. Pregnant women should have the opportunity to be enrolled into appropriately designed COVID-19 vaccine trials whenever the prospect of benefit prevails over the risks $^{[45]}$. At the time of writing this paper, there are a few ongoing clinical trials and observational studies registered at ClinicalTrials.gov which focus on the safety, immunogenicity and reactogenicity of different COVID-19 vaccines in pregnant women.

There are two vaccine trials that are currently underway. The first trial sponsored by BioNTech SE in collaboration with Pfizer aims to evaluate the safety, immunogenicity and tolerability of the BNT162b2 vaccine which will be administered in two doses 21 days apart, in pregnant women between 24 to 34 weeks of gestation ${ }^{[46]}$. Another trial sponsored by Janssen Vaccines \& Prevention B.V. is being conducted to evaluate the safety and reactogenicity of the Ad26.COV2.S vaccine, a recombinant, replication-incompetent human adenovirus type 26 vector given to pregnant women during the second and third trimester of pregnancy ${ }^{[47]}$. These two clinical trials are estimated to be completed only in mid-2022 and mid-2023, respectively. Besides clinical trials, there are six prospective cohort studies and one case-control study that involve pregnant women. These observational studies mainly intend to assess the safety of COVID-19 vaccination in pregnant women in terms of obstetric and neonatal outcomes ${ }^{[48-54]}$.

Furthermore, the CDC has also established the v-safe COVID-19 Vaccine Pregnancy Registry to recruit pregnant women who had received their COVID-19 vaccination during the periconception period or during pregnancy. Information regarding pregnancy outcomes, complications and neonatal complications will be investigated to better understand the potential effects of COVID-19 vaccination on pregnant women and foetuses which will guide 
future recommendations on COVID-19 vaccination for pregnant women. Up to $19^{\text {th }}$ July $2021,5,103$ pregnant women in the US have enrolled themselves in the registry ${ }^{[55]}$.

\section{COVID-19 Vaccine Acceptance among Pregnant Women}

Despite the various COVID-19 vaccination recommendations and guidelines published by governmental authorities in various countries, the pandemic cannot be curbed without widespread acceptance of COVID-19 vaccination by the public and in our context, by pregnant women.

An online cross-sectional survey was conducted in 16 countries, including the Philippines, to gauge the level of acceptance of COVID-19 vaccination among pregnant women. Among 5,282 pregnant women who participated in the survey, 52\% wished to get vaccinated against COVID-19 if there was a 90\% vaccine efficacy. However, the responses varied considerably by country. Mexico and India had the highest COVID-19 vaccine acceptance level where more than $80 \%$ of the pregnant women expressed that they were either "somewhat likely", "fairly likely" or "very likely" to get vaccinated. For the Philippines, the acceptance level was approximately 70\%. In contrast, the COVID-19 vaccine was least accepted in Russia and Australia, where close to $70 \%$ expressed their reluctance about getting vaccinated during pregnancy. The main reasons for vaccine hesitancy were concerns about potential exposure of their baby to side effects, concerns regarding the vaccine approval process as well as insufficient data about the safety and effectiveness of the vaccines in pregnant women ${ }^{[56]}$. Two other similar studies conducted in Turkey and New York also reported a low acceptance rate of $37 \%{ }^{[57]}$ and $44.3 \%{ }^{[58]}$, respectively. On the other hand, relatively high acceptance rates of COVID-19 vaccination among pregnant women were reported in China ${ }^{[59]}(77.4 \%)$ and Ethiopia ${ }^{[60]}(70.7 \%)$.

Significant geographical variation was observed in the COVID-19 acceptance among pregnant women. This might be due to the difference in women's risk perception of COVID19, their lack of trust towards science and public health agencies ${ }^{[56]}$. Hence, vaccination campaigns and targeted efforts should be carried out to boost COVID-19 vaccine confidence among pregnant women.

\section{Conclusion}

In general, most of the countries in Southeast Asia recommended COVID-19 vaccination in pregnant women after taking into consideration that the benefits far outweigh the risks. A few countries have published their COVID-19 vaccination guidelines for pregnant women according to the latest evidence available. For instance, the $\mathrm{MOH}$ in Malaysia just released the third edition of its clinical guidelines on COVID-19 vaccination in July 2021 which included detailed guidelines for the pregnant population. Singapore also 
published a joint guideline on COVID-19 vaccination in June 2021, focusing on pregnant and breastfeeding women and on women who are planning to conceive. These guidelines are extremely useful in providing evidence-informed recommendations about COVID-19 vaccination in pregnancy. Countries like Myanmar and Timor Leste have not published local vaccination guidelines, hence we are unsure about their vaccination program for pregnant women.

There are a few limitations to our study. First, there were official documents and guidelines written in foreign languages that we experienced difficulty in interpreting. This may have resulted in a less comprehensive presentation of related information in this review. Data related to COVID-19 vaccines are rapidly evolving and information contained herein might change in times to come.

Considering the ongoing efforts of researchers around the world, we believe that there will be more evidence regarding COVID-19 vaccination in pregnancy in the future. This will help pregnant women to make the best decision possible and will help healthcare providers to give clearer guidance and advice based on the available evidence.

Author Contributions: JNK and HCL drafted the manuscript. HCL and IL provided review and editing for this manuscript. JNK, HCL and IL conceptualized this review writing project.

Funding: No external funding was provided for this research.

Acknowledgments: We would like to thank the Director-General of Health Malaysia for his permission to publish this article.

Conflicts of Interest: The authors declare no conflict of interest.

\section{References}

1. WHO Coronavirus (COVID-19) Dashboard. 2021. Available at: https://covid19. who.int [Accessed on 24 July 2021].

2. Thailand: How a strong health system fights a pandemic. 2020. Available at: https://www.google.com/url?sa=t\&rct=j\&q=\&esrc=s\&source=web\&cd=\&ved=2ahUKEwi-vKK-

8_3xAhVAzDgGHQ_dDeUQFjALegQIBRAD\&url=https\%3A\%2F\%2Fwww.who.int $\% 2 F d o c s \% 2 F$ default-source $\% 2$ Fcoronaviruse $\% 2$ Fcountry-case-studies $\% 2$ Fthailand-c19-case-study-20september.pdf\%3Fsfvrsn\%3Dd5534183_2\%26download\%3Dtrue\&usg=AOvVaw13R7cfAfAvFRrG Kn02-50W [Accessed on 24 July 2021].

3. Loh HC, Seah YK, and Looi I, The COVID-19 pandemic and diet change. Prog Microbes Mol Biol 2021; 4(1): a0000203.

4. Hoo HE, Loh HC, Ch'ng ASH, et al., Positive impacts of the COVID-19 pandemic and public health measures on healthcare. Prog Microbes Mol Biol 2021; 4(1): a0000221.

5. Joseph RJ and Ser H-L, Stories from the East: COVID-19 Situation in India. Prog Microbes Mol Biol 2021; 4(1): a0000213.

6. Indonesia. 2021. Available at: https://covid19.who.int/region/searo/country/id [Accessed on 24 July 2021]. 
7. Recommendation regarding the spike in cases of pregnant women with COVID-19. 2021. Available at: $\quad$ https://pogi.or.id/publish/wp-content/uploads/2021/06/Revisi-Rekomendasi-POGI-utk-Bumildengan-Covid-19-.pdf [Accessed on 24 July 2021].

8. Knight M, Bunch K, Vousden N, et al., Characteristics and outcomes of pregnant women admitted to hospital with confirmed SARS-CoV-2 infection in UK: national population based cohort study. BMJ 2020; 369: m2107.

9. Allotey J, Stallings E, Bonet M, et al., Clinical manifestations, risk factors, and maternal and perinatal outcomes of coronavirus disease 2019 in pregnancy: Living systematic review and meta-analysis. BMJ 2020; 370: $\mathrm{m} 3320$.

10. Martinez-Portilla RJ, Sotiriadis A, Chatzakis C, et al., Pregnant women with SARS-CoV-2 infection are at higher risk of death and pneumonia: Propensity score matched analysis of a nationwide prospective cohort (COV19Mx). Ultrasound Obstet Gynecol 2021; 57(2): 224-231.

11. Gurol-Urganci I, Jardine JE, Carroll F, et al., Maternal and perinatal outcomes of pregnant women with SARS-CoV-2 infection at the time of birth in England: National cohort study. Am J Obstet Gynecol 2021: S0002-9378(21)00565-2.

12. Loo K-Y, Letchumanan V, Ser H-L, et al., COVID-19: Insights into potential vaccines. Microorganisms 2021; 9(3): 605.

13. Brillo E, Tosto V, Gerli S, et al., COVID-19 vaccination in pregnancy and postpartum. J Matern Fetal Neonatal Med 2021: 1-21.

14. Interim clinical considerations for use of COVID-19 vaccines currently authorized in the United States. 2021. Available at: https:/www.cdc.gov/vaccines/covid-19/clinical-considerations/covid-19vaccines-us.html?CDC_AA_refVal=https\%3A\%2F\%2Fwww.cdc.gov\%2Fvaccines \%2Fcovid19\%2Finfo-by-product\%2Fclinical-considerations.html\#pregnant [Accessed on 24 July 2021].

15. Gray KJ, Bordt EA, Atyeo C, et al., Coronavirus disease 2019 vaccine response in pregnant and lactating women: A cohort study. Am J Obstet Gynecol 2021.

16. Collier A-rY, McMahan K, Yu J, et al., Immunogenicity of COVID-19 mRNA Vaccines in Pregnant and Lactating Women. JAMA 2021; 325(23): 2370-2380.

17. Prabhu M, Murphy EA, Sukhu AC, et al., Antibody response to Coronavirus disease 2019 (COVID19) messenger RNA vaccination in pregnant women and transplacental passage into cord blood. Obstet Gynecol 2021; 137(2): 278-280.

18. Shimabukuro TT, Kim SY, Myers TR, et al., Preliminary findings of mRNA Covid-19 vaccine safety in pregnant persons. N Engl J Med 2021; 384(24): 2273-2282.

19. Bookstein Peretz S, Regev N, Novick L, et al., Short-term outcome of pregnant women vaccinated by BNT162b2 mRNA COVID-19 vaccine. Ultrasound Obstet Gynecol 2021.

20. Shanes ED, Otero S, Mithal LB, et al., Severe Acute Respiratory Syndrome Coronavirus 2 (SARSCoV-2) vaccination in pregnancy: Measures of immunity and placental histopathology. Obstet Gynecol 2021; 138(2): 281-283.

21. Kadali RAK, Janagama R, Peruru SR, et al., Adverse effects of COVID-19 messenger RNA vaccines among pregnant women: A cross-sectional study on healthcare workers with detailed self-reported symptoms. Am J Obstet Gynecol 2021.

22. Loo K-Y and Letchumanan V, COVID-19: Malaysia's fight against this deadly virus. Prog Microbes Mol Biol 2021; 4(1): a0000204. 
23. COVID-19 vaccination during pregnancy and lactation. 2021. Available at: https://www.vaksincovid.gov.my/upload/media/COVID-19-Vaccination-Pregnancy\&LactationENG.pdf?fbclid=IwAR2aNSX64E-ivrszADSz3mqVHVE-mPGB1YQfEPIsXstfOEeVBVGH3VGRGM [Accessed on 24 July 2021].

24. Guidelines on COVID-19 vaccination in pregnancy and breastfeeding. 2021. Available at: https://www.vaksincovid.gov.my/upload/media/Guidelines_on_COVID-

19_Vaccination_in_Pregnancy and Breastfeeding_Version_2_-MOH.pdf [Accessed on 24 July 2021].

25. Chew CH, Yip YY, Vijiakumar J, et al., Real issues for COVID-19 vaccine immunization \& pregnancy, breastfeeding mothers. 2021, Kuala Lumpur, Malaysia: Institute for Clinical Research, NIH MY.

26. Arumugam T, About 6,000 pregnant women to receive Covid-19 vaccine this weekend, in New Straits Time. 2021.

27. Expanding Singapore's vaccination programme: Updated vaccination guidelines for sub-groups of individuals and enhancing access for seniors. 2021. Available at: https://www.gov.sg/article/expanding-singapores-vaccination-programme [Accessed on 24 July 2021].

28. COVID-19 Vaccination for pregnant women, breastfeeding women and women planning to conceive.
2021.
Available
at:
https://www.ams.edu.sg/view-

pdf.aspx?file=media\%5C6131_fi_482.pdf\&ofile=Guidelines_COVID-

$19+$ Vacc+in+Pregnant+\%26+Breastfeeding+Women+and+Women+Planning+to+Conceive+(Final). pdf [Accessed on 24 July 2021].

29. COVID-19 Vaccination. 2021. Available at: https://www.moh.gov.sg/covid-19/vaccination [Accessed on 24 July 2021].

30. Boonma N. A pregnant woman in the year of the cow: How to have a safe pregnancy during COVID19? 2021. Available at: https://www.bangkokhospital-chiangmai.com/en/covid-19-and-pregnancy/ [Accessed on 24 July 2021].

31. Thai FDA approves Pfizer vaccine. 2021. Available at: https://www.bangkokpost.com/thailand/general/2137963/thai-fda-approves-pfizer-vaccine [Accessed on 24 July 2021].

32. The Coronavirus Disease 2019 situation. 2021. Available at: https://ddc.moph.go.th/viralpneumonia/eng/file/situation/situation-no478-010564.pdf [Accessed on 24 July 2021].

33. Can pregnant women get the COVID-19 vaccine? 2021. Available at: https://doh.gov.ph/node/28465 [Accessed on 24 July 2021].

34. Reports of suspected adverse reaction to COVID-19 vaccines (01 March to 18 July 2021). 2021. Available at: https://www.fda.gov.ph/wp-content/uploads/2021/07/Reports-of-Suspected-AdverseReaction-to-COVID-19-Vaccines-as-of-18-July-2021-v1.0.pdf [Accessed on 24 July 2021].

35. HTAC Guidance for Health Care Providers: COVID-19 Vaccine Gamaleya. 2021. Available at: https://hta.doh.gov.ph/2021/05/05/htac-guidance-for-health-care-providers-covid-19-vaccinegamaleya/ [Accessed on 24 July 2021]. 
36. Frequently Asked Questions on COVID-19 Vaccines. 2021. Available at: http://www.moh.gov.bn/Shared\%20Documents/COVID-

19\%20Vaccine/FAQs\%20General\%20Covid\%2019\%20Vaccine 04032021.pdf [Accessed on 24 July 2021].

37. Brunei Darussalam vaccination $2021 . \quad$ Available at: http://www.moh.gov.bn/Shared\%20Documents/COVID-

19\%20Vaccine/Brunei\%20Darussalam\%20Vaccination\%20Strategy\%20V2.pdf [Accessed on 24 July 2021].

38. Information on the Sinopharm COVID-19 Vaccine. 2021. Available at: http://moh.gov.bn/Shared\%20Documents/COVID-19\%20Vaccine/Sinopharm\%20(EN).pdf [Accessed on 24 July 2021].

39. Information on the OXFORD-AstraZeneca COVID-19 Vaccine. 2021. Available at: http://www.moh.gov.bn/Shared\%20Documents/COVID-19\%20Vaccine/AstraZaneca\%20(EN).pdf [Accessed on 24 July 2021].

40. COVID-19 in Viet Nam Situation Report 50. 2021. Available at: https://www.who.int/vietnam/internal-publications-detail/covid-19-in-viet-nam-situation-report-50 [Accessed on 24 July 2021].

41. COVID-19 Vaccines Frequently asked questions (FAQs). 2021. Available at: https://www.unicef.org/laos/sites/unicef.org.laos/files/2021-04/Vaccines\%20FAQ 6\%20April_0.pdf [Accessed on 24 July 2021].

42. Frequently asked questions: Safety of Covid-19 Vaccines. 2021. Available at: https://www.unicef.org/cambodia/stories/frequently-asked-questions [Accessed on 24 July 2021].

43. Clinical guidelines on COVID-19 vaccination in Malaysia, 3rd Edition 2021. Available at: https://covid-19.moh.gov.my/garis-panduan/garis-panduan-

kkm/ANNEX 48 CLINICAL_GUIDELINES_FOR_COVID_IN_MALAYSIA_3rd_EDITION_120 72021.pdf [Accessed on 24 July 2021].

44. Modi N, Ayres-de-Campos D, Bancalari E, et al., Equity in coronavirus disease 2019 vaccine development and deployment. Am J Obstet Gynecol 2021; 224(5): 423-427.

45. Beigi RH, Krubiner C, Jamieson DJ, et al., The need for inclusion of pregnant women in COVID-19 vaccine trials. Vaccine 2021; 39(6): 868-870.

46. Study to evaluate the safety, tolerability, and immunogenicity of SARS CoV-2 RNA vaccine candidate (BNT162b2) against COVID-19 in healthy pregnant women 18 years of age and older. 2021. Available at: https://clinicaltrials.gov/ct2/show/NCT04754594 [Accessed on 24 July 2021].

47. A Study of Ad26.COV2.S in healthy pregnant participants (COVID-19) (HORIZON 1). 2021. Available at: https://clinicaltrials.gov/ct2/show/study/NCT04765384 [Accessed on 24 July 2021].

48. Observational Maternal COVID-19 Vaccination Study. 2021. Available at: https://clinicaltrials.gov/ct2/show/NCT04826640 [Accessed on 24 July 2021].

49. COVID-19 Vaccines International Pregnancy Exposure Registry (C-VIPER). 2021. Available at: https://clinicaltrials.gov/ct2/show/NCT04705116 [Accessed on 24 July 2021].

50. COVID-19 antibodies in pregnant women and their connection to beta cell function in the fetus. 2021 . Available at: https://clinicaltrials.gov/ct2/show/NCT04860908 [Accessed on 24 July 2021]. 
51. COVID-19 pregnancy related immunological, clinical and epidemiological factors and perinatal outcomes (COVID-PRICE). 2021. Available at: https://clinicaltrials.gov/ct2/show/NCT04659759 [Accessed on 24 July 2021].

52. Active pharmacovigilance study of adsorbed COVID-19 (inactivated) vaccine. 2021. Available at: https://clinicaltrials.gov/ct2/show/NCT04845048 [Accessed on 24 July 2021].

53. COVID-19 and Obstetric Transmission (COVIDOB). 2021. Available at: https://clinicaltrials.gov/ct2/show/NCT04418557 [Accessed on 24 July 2021].

54. Moderna COVID-19 vaccine mRNA-1273 observational pregnancy outcome study. 2021. Available at: https://clinicaltrials.gov/ct2/show/NCT04958304 [Accessed on 24 July 2021].

55. V-safe COVID-19 vaccine pregnancy registry. 2021. Available at: https://www.cdc.gov/coronavirus/2019-ncov/vaccines/safety/vsafepregnancyregistry.html] [Accessed on 24 July 2021].

56. Skjefte M, Ngirbabul M, Akeju O, et al., COVID-19 vaccine acceptance among pregnant women and mothers of young children: Results of a survey in 16 countries. Eur J Epidemiol 2021; 36(2): 197-211.

57. Goncu Ayhan S, Oluklu D, Atalay A, et al., COVID-19 vaccine acceptance in pregnant women. Int J Gynaecol Obstet 2021; 154(2): 291-296.

58. Sutton D, D'Alton M, Zhang Y, et al., COVID-19 vaccine acceptance among pregnant, breastfeeding, and nonpregnant reproductive-aged women. Am J Obstet Gynecol 2021; 3(5): 100403.

59. Tao L, Wang R, Han N, et al., Acceptance of a COVID-19 vaccine and associated factors among pregnant women in China: A multi-center cross-sectional study based on health belief model. Hum Vaccin Immunother 2021: 1-10.

60. Mose A and Yeshaneh A, COVID-19 vaccine acceptance and its associated factors among pregnant women attending antenatal care clinic in southwest Ethiopia: Institutional-based cross-sectional study. Int J Gen Med 2021; 14: 2385-2395. 